\title{
PELATIHAN "ENGLISH FOR GUIDING” BAGI PEMANDU WISATA LOKAL KABUPATEN PURWOREJO
}

\author{
Pratika Ayuningtyas*1 \\ 1.Politeknik Sawunggalih Aji \\ *e-mail: pratika.ayuningtyas@gmail.com ${ }^{1}$
}

\begin{abstract}
The development of tourism village in Purworejo has massive impact to the visitors of the tourism regency. The tourism village has a community which manage and responsible to the single detail of it. One of the important parts of the managerial tourism is the tour guide. With the massive movement of foreign tourist, it is necessary for the tour guide to be able to communicate using English. Based on this fact, therefore, an English training for guides was held. The participants of the training is the tour guide from all over area in Purworejo. Finishing the training, the participants felt that their English skill was improved, mainly on their language expression. The handout that they got was also essential for their skill improvement. Moreover, the instructor could handle the class well as they were given opportunity to show their ability as well astheir weakness. Lastly, the method used for the training was interesting and facilitating.
\end{abstract}

\section{Keywords: training, English for Guiding, Language expression}

\section{Abstrak}

Adanya pembangunan desa wisata di sejumlah desa di Kabupaten Purworejo meningkatkan jumlah wisatawan yang berkunjung. Pengelolaan desa wisata diserahkan kepada pengelola yaitu kelompok atau Lembaga yang bertanggung jawab dalam segala sesuatunya tentang desa wisata. Salah satu bagian dari pengelola adalah pemandu wisata. Dengan banyaknya wisatawan mancanegara yang dating di desa wisata yang ada di kabupaten Purworejo, dibutuhkan pemandu wisata yang mahir berbahasa Inggris. Berangkat dari permasalahan ini, maka Pelatihan English for Guiding dilaksanakan. Pesertaa dari pelatihan ini yaitu para pemandu wisata (tour guide) yang ada di Kabupaten Purworejo. Setelah menjalani pelatihan selama dua hari, para peserta merasakan langsung dampaknya. Antara lain: meningkatnya kemampuan bahasa Inggris yang berfokus pada language expression, bermanfaatnya materi handout yang diberikan pada saat pelatihan dan tepatnya Teknik yang digunakan dalam penyampaian materi pelatihan.

Kata kunci: Pelatihan, English for Guding, language expression

\section{PENDAHULUAN}

Kepariwisataan di kabupaten Purworejo meningkat pesat dalam beberapa tahun terakhir ini. Menurut Pemerintah Kabupaten Purworejo, wisatawan yang berkunjung sampai akhir tahun 2019 adalah sebanyak 456.031 pengunjung. Jumlah tersebut mengalami kenaikan sebesar lima persen (5\%) dari tahun 2018 dengan jumlah wisatawan sebanyak 435.656 orang (Purworejo, 2020). Adanya pembangunan desa wisata di sejumlah desa di Kabupaten Purworejo tampaknya mempengaruhi fenomena peningkatan pengunjung yang terjadi

Menurut Peraturan Daerah Kabupaten Purworejo No 15 Tahun 2019, desa wisata adalah Desa Wisata adalah suatu bentuk integrasi antara atraksi, akomodasi, dan fasilitas pendukung yang disajikan dalam suatu struktur kehidupan masyarakat yang menyatu dengan tata cara dan tradisi yang berlaku (Perda Kab Purworejo, 2019). Tercatat ada empat puluh 
satu (41) desa wisata di Kabupaten Purworejo yang tersebar di berbagai wilayah Kecamatan Purworejo (RadarJogja, 2020). Pemerintah daerah merupakan unsur penyelenggara dengan desa sebagai pelaksana teknisnya.

Pengelolaan desa wisata diserahkan kepada pengelola yaitu kelompok atau Lembaga yang bertanggung jawab dalam segala sesuatunya tentang desa wisata. Tujuan dari dibentuknya desa wisata yaitu untuk meningkatkan kesadaran masyarakat dalam upaya pelestarian dan pendayagunaan potensi alam, menjamin pelestarian nilai-nilai budaya local dan meningkatkan perekonomian dan kesejahteraan masyarakat desa (Perda Kab Purworejo, 2019). Salah satu bagian yang tak terpisahkan dari pengelolaan tempat wisata adalah adanya pemandu wisata (tour guide).

Pramuwisata atau tour guide diartikan sebagai setiap orang yang memimpin kelompok yang terorganisir untuk jangka waktu singkat maupun jangka waktu yang panjang. Pramuwisata memiliki tugas yang cukup berat dalam rangka memberikan pelayanan dan informasi kepada wisatawan dengan sebaik-baiknya. Pramuwisata dituntut memiliki wawasan yang luas, menguasai medan perang dan memiliki keterampilan kerja yang menunjang tugastugasnya (SUDANA, 2015). Salah satu keterampilan (skill) yang harus dimiliki seorang pramuwisata (tour guide) yaitu kemampuan berbahasa asing.

Salah satu bahasa asing adalah bahasa Inggris. Bahasa Inggris merupakan bahasa global yang dapat digunakan di seluruh dunia, maka dengan menguasai bahasa Inggris, kemampuan berkomukasi akan meningkat (Firdaus, 2014). Selain itu, tercatat pula adanya 240 - 248 wisatawan mancanegara yang berkunjung ke kabupaten Purworejo pada tahun 2018 - 2019 (Wahyudin, 2018). Dengan adanya fakta-fakta ini, pelatihan bahasa Inggris untuk para pemandu wisata (tour guide) mutlak diperlukan.

Kegiatan pelatihan bahasa Inggris telah terbukti dapat meningkatkan kemampuan berkomunikasi para pemandu wisata (tour guide) (I N Sudipa, 2014; Rahmawati, I., \& Allen, 2015; Sudipa et al., 2010). Selebihnya, peningkatan kemampuan para pemandu wisata ini juga diharapkan dapat seiring dengan peningkatan kualitas hidup masyarakat di sekitar desa wisata (Wahyudin, 2018). Maka dengan beberapa referensi yang ada Dinas Koperasi Industri Perdagangan dan Pariwisata (DINKOPERINDAGPAR) sebagai penggagas kegiatan menggandeng Dinas Arsip dan Perpustakaan Daerah (DINARPUSDA) kemudian menunjuk Politeknik Sawunggalih Aji sebagai Lembaga penyelenggara kegiatan pelatihan ini. Pelatihan ENGLISH FOR GUIDING terselenggara atas kerja sama ketiga pihak tersebut diatas.

Pelatihan ini bertujuan untuk meningkatkan kemampuan bahasa Inggris dasar para pemandu wisata yang meliputi language expression dan kosa kata, pengucapan, tata bahasa dan kelancaran berbicara. Berkaitan dengan memandu wisata, beberapa language function yang lazim digunakan adalah menyapa, menjelaskan aturan, menjelaskan keamanan, menjelaskan etiket dan adat istiadat, menunjukkan tempat-tempat yang menarik, menjawab pertanyaan tamu (Ayu et al., 2017). Maka diharapkan di akhir pelatihan ini, peserta mampu menguasai ekspresi dasar dalam menerima, menjamu serta menjelaskan kepada para wisatawan mancanegara.

\section{METODE}

Tahapan persiapan meliputi mendata peserta yang akan mengikuti pelatihan dan kesiapan instruktur yang merupakan penulis sendiri, menyusun jadwal kegiatan, menyusun materi dan mempersiapkan tempat untuk kegiatan berlangsung. 
Ada beberapa langkah dalam pelaksanaan kegiatan pengabdian pada masyarakat. Langkah-langkah tersebut yaitu:

1. Melakukan wawancara sebagai basis data kemampuan peserta pelatihan. Wawancara dilakukan sebelum pelatihan dimulai, secara bergantian untuk masingmasing peserta pelatihan. Disamping mengetahui kemampuan awal para guide, pengaruh perlakuan pun diyakini dapat tampak (Jelantik Swasta, 2014). Selain itu, tujuan dari wawancara ini adalah untuk mengetahui langkah-langkah para guide yang dilakukan ketika melaksanakan tugasnya menemani wisatawan, mengidentifikasi language expression yang digunakan, kosa kata dan tata bahasa yang diperlukan oleh para guide.

2. Menggandakan materi pelatihan.

3. Memberikan pelatihan. Pelatihan yang diberikan akan skil berbicara dan akan meliputi elemen kosa kata dan language expression, pengucapan dan tata bahasa. Pelatihan diberikan dengan metode ceramah, drilling, diskusi, peer teaching, dan presentasi

4. Melakukan evaluasi terhadap program, proses dan hasil kegiatan.

\section{HASIL DAN PEMBAHASAN}

Kegiatan ini dilaksanakan pada tanggal 13 Desember 2016 dan 14 Desember 2016. Kegiatan ini berupa pelatihan English for Guiding untuk para guide lokal dari beberapa desa wisata di Kabupaten Purworejo. Pemberi materi adalah tim pelaksana sendiri, yaitu Pratika Ayuningtyas. Seperti yang telah dibahas sebelumnya, materi pelatihan akan berfokus pada language expression seperti menyapa, menyambut tamu dan menawarkan bantuan serta menjelaskan objek. Materi kegiatan pelatihan dapat dilihat pada Tabel 1 di bawah ini.

Tabel 1. Materi Kegiatan Pelatihan

\begin{tabular}{cccc}
\hline pertemuan & tanggal & \multicolumn{1}{c}{ materi } & pemateri \\
\hline 1 & 13 Desember 2016 & Say it in English & Pratika Ayuningtyas \\
& & & \\
& & Expressions of & \\
& & greeting & \\
& & Expressions of & \\
& & welcoming guest & \\
& & Expressions of & \\
& offering help &
\end{tabular}

$2 \quad 14$ Desember $2016 \quad$ Practice explaining an object $\quad$ Pratika Ayuningtyas

Kegiatan pelatihan bahasa Inggris untuk para guide lokal tentunya sangat berguna bagi mereka dalam menjalankan tugas mereka dalam melayani tamu di area desa wisata di kebupaten Purworejo. Motivasi mereka untuk mengikuti pelatihan sangat tinggi, yang dapat dilihat dari keaktifan mereka dalam mengikuti pelatihan. Para peserta pelatihan datang tepat waktu, meskipun jarak dari tempat mereka dengan tempat pelatihan cukup jauh. Jarak terjauh 
yang ditempuh oleh peserta pelatihan adalah kurang lebih 45 menit perjalanan dengan mengendarai sepeda motor. Setelah mengisi presensi, para peserta kemudian masuk ruang pelatihan. Sebelum pelatihan dimulai, para peserta pelatihan mendapat satu bendel materi pelatihan yang berbentuk modul atau handout. Materi pelatihan bentuk print out diberikan kepada semua peserta pelatihan sehingga seandainya sewaktu-waktu mereka perlu berlatih lagi, mereka akan bisa melakukannya sendiri.

Pelatihan dimulai dengan pembukaan oleh wakil bupati, kemudian dilanjutkan dengan pesan dari kepala DINKOPERINDAGPAR dan kemudian acara inti, yaitu pelatihan. Peserta yang hadir mendapatkan kesempatan untuk dapat bertanya, berdiskusi dan mempresentasikan hasil belajarnya. Semua peserta terlihat antusias dengan banyak mengajukan pertanyaan dan aktif berdiskusi. Para peserta pun tidak sungkan untuk berlatih dengan teman sejawatnya. Seperti terlihat pada Gambar 1 berikut.

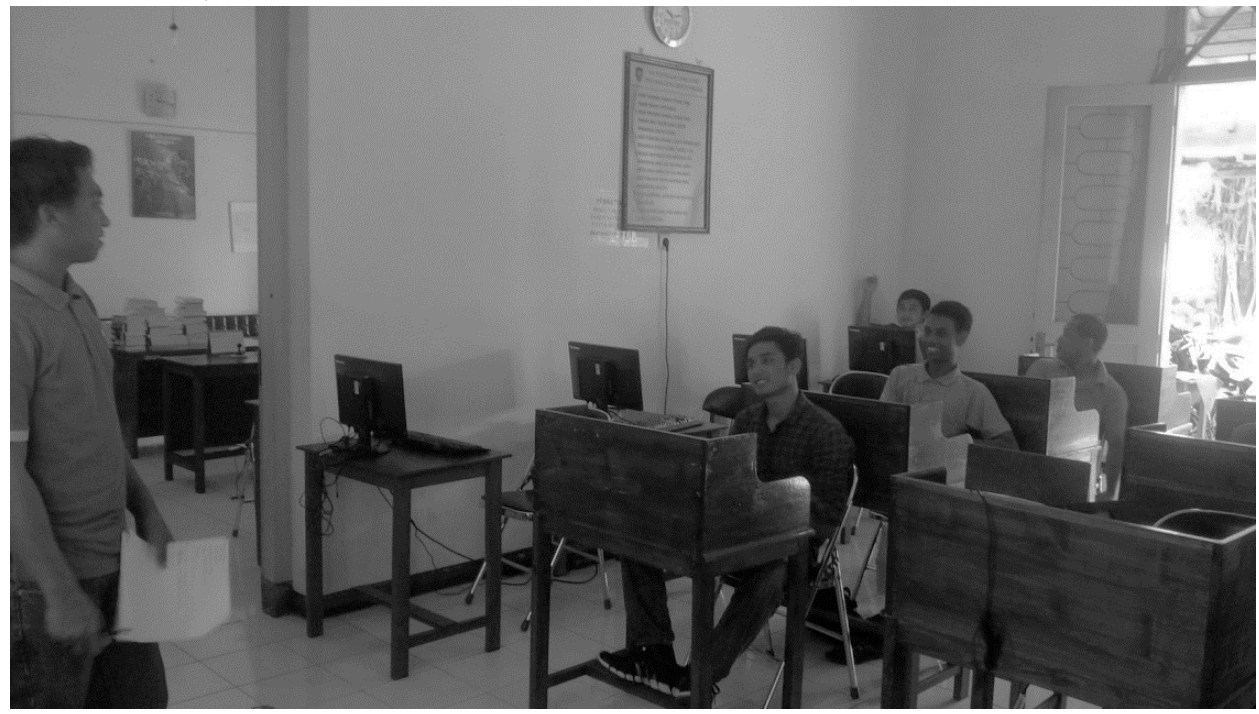

Gambar 1. Peserta berlatih dengan teman sejawat

Dalam pelaksanaan kegiatan tersebut, para peserta banyak bertanya kepada tim pelaksana, terutama terkait sruktur kalimat, memilih kalimat yang sopan untuk disampaikan kepada tamu dan bahasa Inggris dari beberapa kosa kata, yang bersifat lokal, konsep tersebut hanya diketahui/terdapat di Purworejo.

Berikut lebih rinci tentang kegiatan pelatihan yang dilaksanakan.

1. Pertemuan I (13 Desember 2016)

Pada hari pertama, setelah mendapat pengarahan tentang deskripsi dan tujuan kegiatan, para guide mengikuti pre-test. Tim pelaksana meminta mereka mengatakan language expressions yang cocok untuk beberapa language functions yang memang mereka gunakan dalam pekerjaan mereka. Hasil pre-test dapat dilihat dalam lampiran. Setelah mengikuti pre-test, mereka mendapat materi important language functions dan expressions

Drilling menjadi pilihan yang tepat ketika melatih kelancaran pengucapan. Drilling juga membiasakan peserta agar terbiasa mengucap kata sesuai dengan aturannya (Andy et al., 2018). Trainer memberikan contohnya dan para peserta akan 
menirukan. Drilling yang diberikan sesuai dengan pengucapan, intonasi serta penekanan pada tiap-tiap language expression. Peserta dapat menirukan ekspresiekspresi ini pada saat pelatihan dilaksanakan dan diharapkan peserta dapat menggunakan ekspresi tersebut ketika berada dalam situasi yang sama (Elly, 2013). Berikut adalah suasana Ketika kegiatan sedang dilaksanakan, seperti dapat dilihat pada Gambar 2.

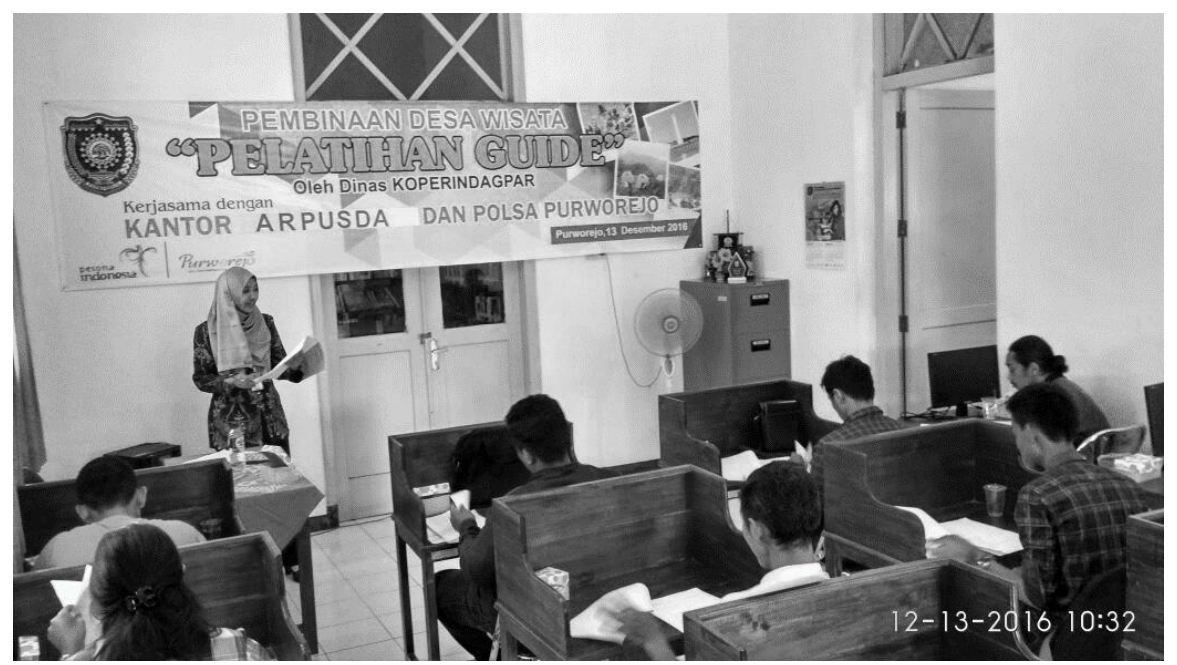

Gambar 2. Peserta berlatih dengan metode drilling

Language functions yang ditekankan adalah greeting, introducing onself, offering guide assistance, informing the guide fee, welcoming the guests to enter the area, explaining about an object, telling a procedure/process/sequence, saying farewell, apologizing dan thanking. Karena para guidesudah biasa melaksanakan pekerjaan mereka, mereka sudah bisa menyucapkan language expression yang diminta dengan baik, namun koreksi dalam pengucapan dan struktur (dalam hal ini tata bahasa) masih diperlukan.

\section{Pertemuan II (14 Desember 2016)}

Pada hari kedua, para guide masih melanjutkan materi important language expressions. Tentu saja materi yang diberikan sesuai dengan kebutuhan pekerjaan mereka. Mereka berlatih melafalkan language expressions yang diberikan dengan intonasi yang pantas/cocok. Tim pelaksana pun membimbing mereka dan mengkoreksi apabila terdapat kesalahan. Para guide yang sudah bisa menyampaikan language expressions yang diperkenalkan dengan pelafalan dan struktur yang benar, sudah mulai berlatih guiding dengan urutan yang ditentukan. Urutan yang ditentukan tersebut sama dengan urutan language functions dan expressions yang diberikan kepada mereka. Pada pertemua kedua ini, pemberi materi juga membimbing para guide cara dan bahasa yang benar dalam menyampaikan penjelasan tentang suatu hal kepada tamu. Di hari terakhir pelatihan ini, materi yang harus dikuasai adalah presentasi atau mengenalkan suatu objekk wisata daam bahasa inggris. Banyak peserta yang berhasil menyampaikan dengan baik dan benar. Namun tidak sedikit pula yang belum dapat memberikan resentasi sesuai dengan standar guiding. Seperti terlihat pada Gambar 3 
di bawah ini.

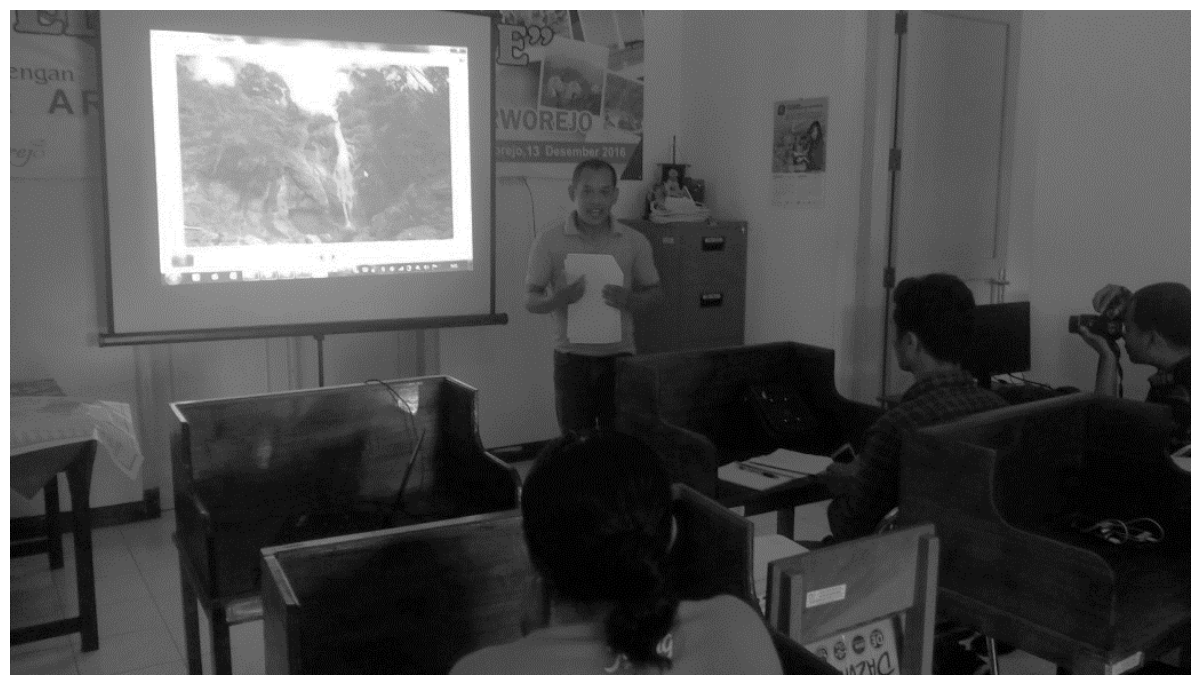

Gambar 3. Peserta menjelaskan tentang objek wisata dari desa masing-masing

Setelah pelatihan berakhir para peserta harus mengisi form evaluasi kegiatan yang harus ditanggapi peserta pelatihan dengan memberikan tanggapan sangat tidak setuju (STS), tidak setuju (TS), setuju (S) dan sangat setuju (SS). Dari hasil evaluasi yang diisi oleh peserta Nampak bahwa pada topik materi pelatihan, para peserta menyatakan tertarik dengan materi pelatihan karena materi pelatihan tersebut relevan atau sesuai dengan bidang pekerjaan yang mereka geluti sehari-hari. Terlebih lagi, materi tersebut bermanfaat bagi para peserta untuk meningkatkan kemampuan bahasa Inggris.

Dalam topik Teknik pengajaran, peserta merasa terbantu dalam memahami materi yang diberikan karena teknik yang digunakan dapat memfasilitasi para peserta. Sedangkan pada topik instruktur atau trainer, para peserta setuju bahwa instruktur menyampaikan materi dengan jelas dan mudah dimengerti. Instruktur juga memberikan kesempatan peserta untuk mengajukan pertanyaan. Pada saat peserta bertanya, instruktur memberikan jawaban yang jelas serta memberikan umpan baliknya. Terlebih lagi, instruktur bersedia membantu peserta yang mengalami kesulitan. Berikut adalah salah satu contoh form umpan balik dari peserta untuk kegiatan pelatihan. 


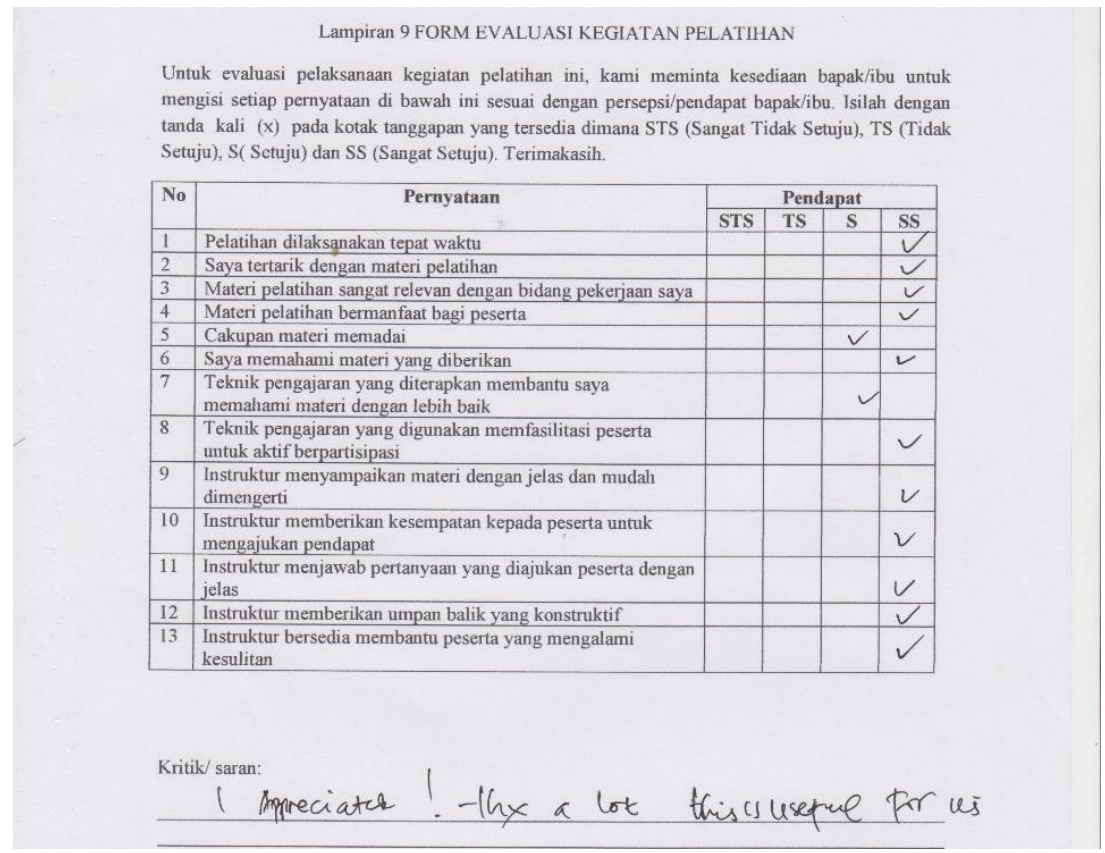

Gambar 4. Form Evaluasi Peserta Pelatihan

\section{KESIMPULAN}

Kegiatan pelatihan ini merupakan kegiatan yang diadakan oleh tiga Lembaga yang berbeda yaitu Dinas Koperasi Industri Perdagangan dan Pariwisata, Dinas Arsip dan Perpustakaan Daerah serta Politeknik Sawunggalih Aji. Pelatihan ini diikuti oleh pemandu wisata (tour guide) yang berasal dari beberapa desa wisata yang ada di Kabupaten Purworejo. Dari pelatihan ini dapat disimpulkan bahwa:

1. Peserta merasa terfasilitasi dengan adanya pelatihan ini

2. Kemampuan Bahasa Inggris Peserta meningkat, terutama dalam language expression

3. Peserta pelatihan antusias dengan materi dan metode pengajaran yang digunakan selama pelatihan

4. Materi pelatihan bermanfaat bagi peserta pelatihan karena relevansinya yang tinggi dengan bidang pekerjaan mereka

5. Instruktur memberikan materi dengan jelas dan mudah dimengeri serta dapat merangkul peserta didik yang masih tertinggal

Dari beberapa besimpulan diatas, diharapkan agar kegiatan semacam ini dapat diadakan secara berlanjut dan terprogram agar para pemandu wisata mauppun penggerak wisata di Kabupaten Purworejo dapat meningkatkan kemampuan berkomunikasi untuk dapat melayani para wisatawan dengan lebih baik lagi.

\section{DAFTAR PUSTAKA}

Andy, A., Rusfandi, R., \& Muzammil, L. (2018). Pelatihan Berbahasa Inggris Dengan Drilling Dan Repetition Bagi Karang Taruna Desa Jedong. Martabe : Jurnal Pengabdian Kepada Masyarakat, 1(2), 42. https://doi.org/10.31604/jpm.v1i2.42-48 Ayu, P., Sudana, P., Agung, A., Barustyawati, S., \& Sonia, K. (2017). Pelatihan Bahasa 
Inggris dan Kecakapan Komputer bagi Pemandu Wisata Lokal Gitgit di Buleleng. 179_ 184.

Elly, E. (2013). Peningkatan Kemampuan Berbicara Melalui Metode Drill Pada Pembelajaran Bahasa Indonesua Kelas IV Sekolah Dasar Usaba Sepotong. In FKIP Universitas Tanjungpura.

Firdaus, N. M. (2014). DAMPAK PELATIHAN BAHASA INGGRIS TERHADAP KEMAMPUAN BERBICARA DAN KEPERCAYAAN DIRI TOURISTS GUIDE (STUDI KASUS DI PKBM BINA TERAMPIL MANDIRI CISARUA BANDUNG BARAT). Jurnal EMPOWERMENT, 4(1), 71-77.

I N Sudipa, I. M. R. dan L. L. (2014). Pelatihan bahasa inggris pemandu wisata lokal di desa kapal. Udaya Mengabdi, 13(2), 93-95.

Jelantik Swasta, I. B. (2014). Peran Pendidikan, Pelatihan Bahasa Inggris, Dan Teknik Kepemanduan Dalam Pengembangan Mina Wisata. Jurnal Cakrawala Pendidikan, 3(3), 474-482. https://doi.org/10.21831/cp.v3i3.2391

Purworejo, P. (2020). Alun-alun Purworejo Jadi Tempat Favorit Untuk Rekreasi. https://purworejokab.go.id/web/read/1350/alun-alun-purworejo-jadi-tempat-favorit-untukrekreasi.html

RadarJogja, U. (2020). Wisata Desa Siap Terima Wisatawan. https://radarjogja.jawapos.com/purworejo/2020/06/17/wisata-desa-siap-terimawisatawan/

Rahmawati, I., \& Allen, B. (2015). Pelatihan Bahasa Asing Bagi Pemandu Wisata di Gua Lowo Kabupaten Trenggalek. J-ADIMAS (Jurnal Pengabdian Kepada Masyarakat), 3(1), 34-37.

SUDANA, I. P. (2015). PROBLEMATIKA KEBIJAKAN SERTIFIKASI PROFESI DI BIDANG USAHA JASA PRAMUWISATA DI BALI. In N. K. Arismayanti \& I. N. S. Arida (Eds.), Paradigma dan Kebijakan Pariwisata (pp. 83-96). Cakra Press.

Sudipa, I. N., Brata, F. I. M., Rajeg, I. M., Laksminy, L. P., \& Rahayuni, N. K. S. (2010). Pelatihan bahasa inggris komunikatif bagi kelompok sadar wisata di desa Carang Sari Badung Utara. Udayana Mengabdi, 9(2), 75-78. https://ojs.unud.ac.id/index.php/jum/article/view/2073/1263

Wahyudin, Y. (2018). Peningkatan Perekonomian Daerah. 2(September).

Peraturan Daerah Kabupaten Purworejo Nomor 15 Tahun 2019. Desa Wisata. 13 Agustus 2019. Lembaran Daerah Kabupaten Purworejo Tahun 2019 No 15 Seri E No 13. Purworejo 